\section{Sialoadenitis bacteriana crónica recurrente de la infancia. Caracterización clínica}

\section{RESUMEN}

La sialoadenitis recurrente es el segundo cuadro inflamatorio más frecuente que afecta a la glándula parótida, precedida por la parotiditis viral. Esta afección tiene un cuadro clínico muy similar a la sialoadenitis, motivo por el cual se debe considerar dentro de los diagnósticos diferenciales. La sialoadenitis recurrente se caracteriza por episodios periódicos de inflamación y aumento de volumen de la glándula parótida acompañados de fiebre y malestar general que alternan con intervalos de remisión en los que la glándula es clínicamente asintomática. En el Instituto Nacional de Pediatría consideramos al concepto Sialoadenitis bacteriana crónica recurrente de la infancia como la definición más específica y completa para referirse a esta enfermedad. Debido a su recurrencia decidimos escribir este artículo para señalar sus características clínicas.

Palabras clave: sialoadenitis bacteriana, sialogogo, glándula parótida, conducto de Stenon.
Carlos Ávila-Sánchez ${ }^{1}$ Jorge Téllez-Rodríguez ${ }^{2}$ Rubí López-Fernández²

${ }^{1}$ Residente de segundo año de la Especialidad en Estomatología Pediátrica.

${ }^{2}$ Cirujano Maxilofacial adscrito al Servicio de Estomatología Pediátrica.

Instituto Nacional de Pediatría, Ciudad de México.

\section{Childhood chronic recurrent bacterial sialadenitis. Clinical characterization}

\begin{abstract}
Recurrent sialadenitis is the second most common inflammatory condition that affects the parotid gland, preceded by viral parotitis; pathology is it clinically very similar to sialadenitis, for which reason in should be considered in the differential diagnosis. Recurrent sialadenitis is characterized by periodic inflammatory episodes increased volume of the in the parotid gland, fever and malaise, alternating with intervals of remission, in which the gland is clinically asymptomatic. In our experience at the National Institute of Pediatrics, we consider the term chronic recurrent bacterial sialadenitis of childhood, as the specific and complete definition of this disease. In view of its recurrence, we decided to write this article indicating clinical characteristics of this pathology.
\end{abstract}

Key words: bacterial sialadenitis, sialogogue, parotid gland, Stenon duct.
Recibido: 20 de febrero del 2014

Aceptado: 25 de septiembre del 2014

Correspondencia: Dr. Jorge Téllez-Rodríguez/Dra. Rubí López-Fernández Instituto Nacional de Pediatría. Insurgentes Sur 3700-C CP 04530 México, D.F.

Tel: 10840900 ext: 1219 jorgetellezmaxilo@hotmail.com dra_rubylopez@yahoo.com.mx

Este artículo debe citarse como Ávila-Sánchez C, Téllez-Rodríguez J, López-Fernández R. Sialoadenitis bacteriana crónica recurrente de la infancia. Caracterización clínica. Acta Pediatr Mex 2015;36:114-121. 


\section{INTRODUCCIÓN}

Las glándulas salivales forman parte de las glándulas exocrinas del sistema digestivo, son un conjunto de células dispuestas en forma tubuloacinar cuya función es sintetizar la saliva que se vierte en la cavidad oral. ${ }^{1,2}$

Los procesos inflamatorios de las glándulas salivales tienen múltiples causas, la más común es la infecciosa. Estos cuadros se denominan sialoadenitis y en su desarrollo influyen factores locales: cambios en la composición y calidad de la saliva secretada o alteraciones morfofisiológicas de los conductos salivales; y generales: alteraciones de los mecanismos inmunitarios del paciente. ${ }^{1-7}$ Las glándulas más afectadas son las parótidas (una o ambas) y, ocasionalmente, las glándulas submandibulares; durante un episodio pueden estar afectadas varias glándulas. , $^{1,5,5,8,9}$

La glándula parótida se localiza en la celda parotídea, entre las fascias parotídea y cervical; está formada por un lóbulo superficial y uno profundo, entre los que se sitúa el nervio facial y sus ramas motoras. Es inervada por el nervio glosofaríngeo. Su secreción salival es serosa, sin mucina, muy fluida y es más abundante durante la deglución. Su conducto excretor o conducto de Stenon mide aproximadamente $5 \mathrm{~cm}$ de longitud, se desprende de la glándula a nivel de su porción anterior, atraviesa el músculo masetero hacia dentro en su borde anterior y la bola adiposa de Bichat y perfora el músculo buccinador; desde allí se dirige hacia adelante y desemboca en un orificio pequeño a nivel del primero o segundo molar superior. Su recorrido es muy tortuoso y por ello de fácil colonización bacteriana. ${ }^{1,2,4,9,10}$

\section{Definición}

La sialoadenitis es la inflamación de las glándulas salivales, generalmente debida a una infección bacteriana en los conductos excretores. Ocurre con mayor frecuencia de forma unilateral en las glándulas parótidas. Puede ser una afección aguda o crónica y recurrente. Es una entidad frecuente en niños entre 8 meses y 16 años de edad. ${ }^{1,6-8,11-13}$ Existen diversos sinónimos para este padecimiento: parotiditis recurrente juvenil, sialoadenitis supurativa, parotiditis supurativa y parotiditis piógena infantil. ${ }^{3-5,8,14}$

\section{Epidemiología}

En la infancia la frecuencia máxima de incidencia es entre 2 y 7 años de edad, con una distribución igual en ambos géneros. Es una enfermedad poco frecuente en pacientes adultos, aun cuando existen reportes de casos en ese grupo de edad ${ }^{3,5,8}$ es más común durante la tercera a cuarta décadas de la vida y es más frecuente en mujeres con una relación hombre-mujer de $1: 7 \cdot 5 \cdot 5,8,15$

\section{Etiología}

La sialoadenitis bacteriana está condicionada por el estado inmunológico del paciente y por la disminución del flujo salival. En la mayoría de los casos existe el antecedente de una infección viral que afectó al parénquima glandular. 1,3,7,15,16 Los factores que predisponen esta enfermedad son deshidratación, neoplasias orales, inmunodepresión, sialolitiasis y el uso de medicamentos que disminuyen la salivación. Otros factores son la malnutrición (déficit en la absorción) y la desnutrición, por deficiencia de diversos nutrientes, específicamente de proteínas y aminoácidos. ${ }^{17,18}$

La etiopatogenia de esta entidad clínica se ha relacionado con sensibilizaciones alérgicas, alteraciones inmunológicas, infecciones y malformaciones congénitas del conducto; a pesar de los diversos estudios la etiología sigue siendo idiopática. ${ }^{1,4,5,8,11,15}$ En la edad pediátrica influyen varios factores en la aparición de la sialoadenitis 
crónica recurrente como la inmadurez inmunológica, hábitos nocivos a la salud: succión digital, onicofagia, o cualquier otro hábito que propicie la introducción de objetos sucios en la boca y mala higiene bucal, que favorecen la colonización microbiana retrógrada del conducto y de la glándula parótida. ${ }^{13,6,8}$

Se han postulado diversas teorías según el factor predisponente, ya sea infección, inmunodepresión, obstrucción, alteraciones anatómicas congénitas, infiltración linfocítica, efectos posquirúrgicos y trastornos autoinmunitarios. ${ }^{1,3,8,11,17}$ De ellas, la más importante y sustentada es la teoría infecciosa por inoculación bacteriana originada en los conductos excretores a partir de los microorganismos de la cavidad bucal; en ésta las bacterias ascienden por los conductos salivales en forma retrógrada y provocan la obstrucción de los ductos salivales e interrumpen la producción de saliva o mediante la llegada de los microorganismos a las glándulas por la sangre, por la linfa (infrecuente) o por obstrucción o higiene oral deficiente (caries). ${ }^{1,3,4,8}$

Los agentes causales más frecuentes de sialoadenitis aguda son Staphylococcus aureus, seguido de estreptococos (Streptococcus pneumoniae, pyogenes, viridans y salivarius), bacilos aerobios gramnegativos (Escherichia coli) y ocasionalmente Haemophilus influenzae; en forma crónica son estafilococos, estreptococos y bacilos gramnegativos aerobios: E. coli, Serratia, Pseudomonas y Klebsiella spp. y anaerobios estrictos: Porphyromonas, Prevotella, Fusobacterium y Peptostreptococcus. ${ }^{1,3,4,13,17,19-21}$ Es importante considerar que la sialoadenitis no necesariamente es resultado de factores aislados y se deben tomar en cuenta todas las posibles causas.

Anatomía patológica

Las glándulas con sialoadenitis se encuentran uniformemente aumentadas de tamaño; existe inflamación leve del epitelio ductal causado por sialectasia debida a deshidratación o estados de debilidad general. En infecciones graves puede haber periadenitis con edema e infiltrado inflamatorio de los tejidos vecinos que, posteriormente, se convierten en bridas fibróticas que fijan la glándula. Microscópicamente hay infiltrado agudo de los ácinos glandulares con edema y distensión. Los conductos están dilatados e infiltrados por células de inflamación aguda, con distorsión de la estructura ductal distal, metaplasia y alteración del epitelio. El infiltrado de linfocitos mononucleares, que son los encargados de lesionar el retículo ductal, genera extravasación de la secreción al parénquima glandular y perpetúa la inflamación, dando como resultado una leucocitosis. La sialoadenitis no es un proceso preneoplásico. ${ }^{1,11,22,23}$

En caso de no encontrar un factor desencadenante demostrable se debe evaluar la posibilidad de una sialoadenitis mioepitelial o lesión linfoepitelial benigna, que es un proceso inflamatorio periductal de la glándula salival, lo que a la larga provoca el reemplazo parcial o total del parénquima glandular con metaplasia del sistema ductal. ${ }^{24}$

\section{Cuadro clínico}

Los pacientes tienen diversos signos y síntomas, locales y sistémicos, que comprometen su estado general y emocional, alejándolos de sus actividades lúdicas y escolares. ${ }^{711}$ En la glándula afectada hay dolor y el paciente muestra una actitud defensiva durante el examen físico. ${ }^{1,6,11}$ El dato fundamental de la sialoadenitis es el aumento de volumen de la glándula afectada, que inicialmente tiene consistencia blanda y causa elevación del lóbulo de la oreja del lado de la glándula afectada, signo patognomónico de esta afección (Figura 1). ${ }^{1,8,11}$

En la sialoadenitis aguda hay fiebre, tumefacción, dolor que limita la apertura bucal y 


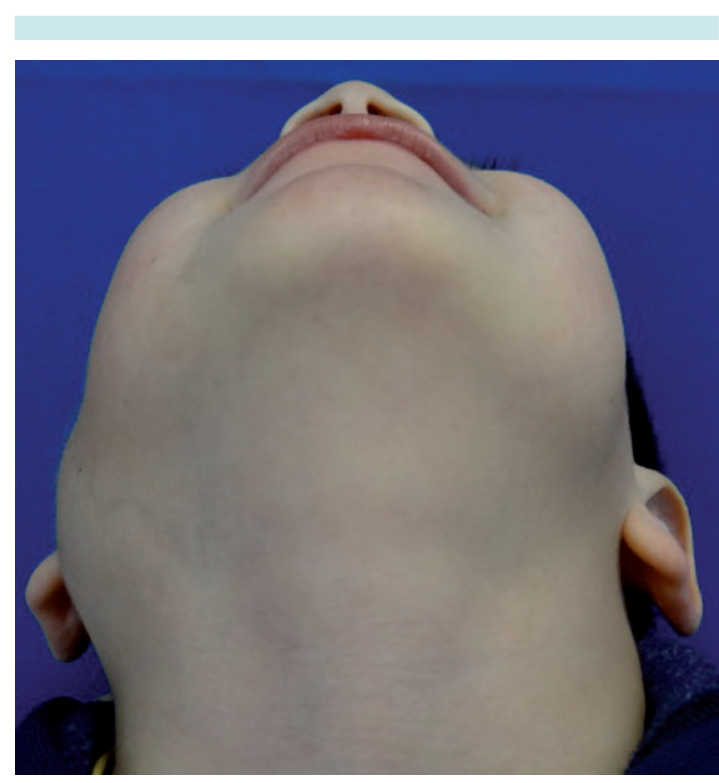

Figura 1. Vista inferior que muestra aumento de volumen en la zona de la glándula parótida y elevación del lóbulo de la oreja derecha.

otalgia; malestar general, irritabilidad, anorexia, trismo, celulitis (edema, eritema y calor) de la piel circundante; por las carúnculas de la desembocadura del conducto puede salir espontáneamente saliva turbia o purulenta al realizar presión sobre la acumulación, por lo que el cuadro clínico recibe el nombre de sialoadenitis bacteriana aguda supurativa ( $\mathrm{Fi}$ gura 2). ${ }^{1,3,13,22}$ Usualmente, ocurren episodios inflamatorios repetitivos, separados por períodos asintomáticos y sin enfermedad sistémica acompañante, tres a cuatro veces por año, lo que hace al cuadro clínico un proceso crónico que da lugar a una sialoadenitis bacteriana crónica y recurrente. El aumento de volumen de la glándula se estabiliza con la consiguiente fibrosis del parénquima glandular que se manifiesta por una consistencia dura de carácter nodular de toda la glándula. ${ }^{1,5,8}$ Cuando el cuadro es agudo se puede presentar de forma bilateral; en casos crónicos, casi siempre es unilateral.

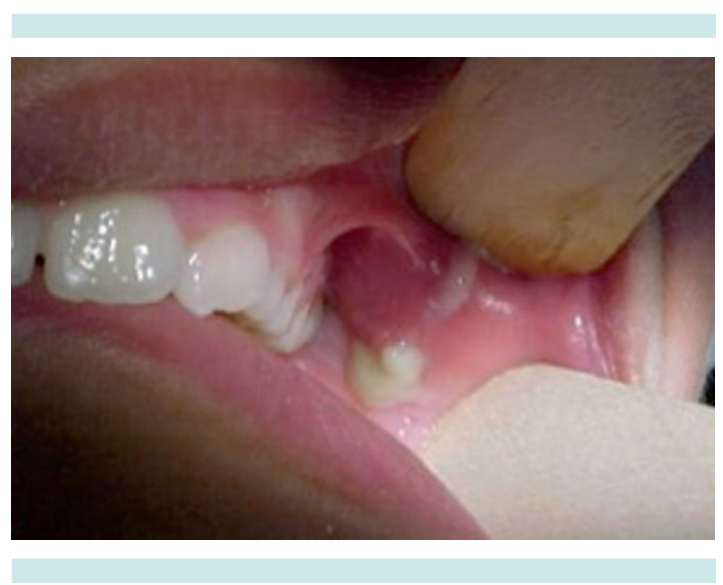

Figura 2. Salida de líquido purulento por el conducto de Stenon.

Si la infección no se elimina en etapa temprana la supuración se extiende más allá de la cápsula de la glándula parótida, a lo largo de los planos faciales, y puede generar una fístula cutánea. 1,5,11 De acuerdo con la periodicidad del cuadro clínico durante un año se puede clasificar en leve: hasta tres episodios de sialoadenitis bacteriana, sin importar su magnitud ni la parótida afectada; moderada: de cuatro a diez procesos infecciosos parotídeos previos y severa: más de diez infecciones parotídeas previas o persistencia de inflamación glandular, aún en los periodos intercrisis, con pus escaso en el conducto salival. ${ }^{5,8}$ Son indicaciones de hospitalización la deshidratación, enfermedad de base no controlada y el desarrollo de un absceso o extensión a espacios cervicales profundos. ${ }^{1,6}$

\section{Diagnóstico}

El diagnóstico se basa en la historia y en la exploración clínica; se confirma con ultrasonografía que es el estudio de elección para el diagnóstico y seguimiento de esta enfermedad..$^{7,8,10} \mathrm{La}$ exploración clínica de la glándula parótida y su conducto excretor se debe realizar de forma bimanual buscando el orificio de salida del conducto a nivel del primer o segundo molar 
superior. En forma simultánea se debe realizar una palpación en el sentido del drenaje de la glándula para corroborar su permeabilidad. Una vez ubicada la carúncula del conducto se debe secar y cubrir con una gasa; posteriormente se solicita al paciente que degluta unas gotas de limón y se retira la gasa para estimular y comprobar la salida de saliva a través del conducto. ${ }^{1,5,11}$

Entre los estudios auxiliares de diagnóstico se encuentran:

- Biometría hemática.

- Ecografía de alta resolución.

- Sialografía por resonancia magnética nuclear simple y contrastada/por sustracción digital.

- Sialoendoscopia parotídea.

- Tomografía axial computada.

- Biopsia por aspiración con aguja fina.

- Gammagrafía de glándulas salivales.

- Ultrasonografía Doppler.

- Diagnóstico microbiológico. 1,3,6,8,25-31

\section{Diagnóstico diferencial}

El diagnóstico diferencial se establece con:

- Sialoadenosis.

- Síndrome de Sjögren.

- Sialoadenitis crónica esclerosante (tumor de Kuttner).

- Enfermedad de Mikulicz’s (lesión linfoepitelial benigna) y de MelkerssonRosenthal.

- Parotiditis viral.

- Adenoma pleomorfo.

- Tumor de Whartin.

- Hipertrofia de masetero.

- Parotiditis causada por intubación orotraqueal.

- $\quad$ Sialolitiasis. ${ }^{1-3,9,13,14,29,30,32-35}$
Tratamiento

En un estudio retrospectivo realizado en el Instituto Nacional de Pediatría, del 1 de enero de 2004 al 31 de diciembre de 2007, se dio tratamiento estomatológico de urgencia a 14 niños con diagnóstico de sialoadenitis. ${ }^{36}$ En niños y adolescentes el tratamiento es conservador, ya que en $95 \%$ remite después de la adolescencia sin necesidad de tratamiento. ${ }^{8}$

En la fase aguda el tratamiento incluye:

Antibióticos: con cobertura para estafilococos y estreptococos. Dicloxacilina y amoxicilina con ácido clavulánico son antibióticos de primera elección. En casos de alergia a derivados de la penicilina se debe usar clindamicina o vancomicina. ${ }^{1,4,6,8,23,37}$ Se debe considerar la prevalencia local de $S$. aureus resistente a la meticilina.

Antiinflamatorios no esteroides: ibuprofeno cuando existen datos clínicos de inflamación ganglionar. Sólo en casos especiales se debe valorar el uso de antiinflamatorios esteroides como la metilprednisolona. ${ }^{6,8}$

Analgésicos: el paracetamol es el medicamento que más se utiliza y se puede administrar junto con ibuprofeno. ${ }^{1,6}$

Sialogogos: un sialogogo es una sustancia, alimento o fármaco, que estimula la secreción de las glándulas salivales. Se debe indicar agua con zumo de limón, caramelos ácidos, preparados de xilitol, pilocarpina o neostigmina. Estos dos últimos parasimpaticomiméticos con efectos adversos considerables, por tanto se deben usar en casos seleccionados. . $^{1,3,6-8}$

Termoterapia: se colocan medios físicos locales como fomentos calientes húmedos en la zona afectada. ${ }^{1,6,13}$ 
Hidratación: el consumo abundante de líquidos estimula la formación de saliva y mantiene permeables los conductos excretores. ${ }^{1,3,6,13}$

Fisioterapia: realizar masaje extra- e intraoral en el sentido del drenaje (saliva o pus) de la glándula a través de su conducto excretor. ${ }^{7}$

Medidas higiénicas: se debe practicar una buena higiene oral consistente en cepillado dental minucioso y una limpieza con hilo dental, por lo menos dos veces al día, para disminuir el grado de colonización de bacterias en la cavidad bucal. Así mismo, evitar la introducción de objetos y manos sucias en la boca. ${ }^{1,6}$

Vitaminoterapia: algunos autores sugieren el tratamiento inmunomodulador con levamisol, vitamina $B_{1}$, vitamina $B_{6}$ y clorfenamina. ${ }^{5,6}$

Dilatación del conducto de Stenon: se realiza con una sonda lagrimal mientras se estimula la glándula con ingestión de cítricos. ${ }^{13}$

En los casos graves, que no mejoran con el tratamiento médico, con más de cuatro o cinco episodios por año, o en quienes por su diagnóstico de base se requiere eliminar el foco infeccioso de forma rápida, el tratamiento quirúrgico es el adecuado. ${ }^{1,4,8}$

Si existe un absceso, se puede drenar quirúrgicamente o con una punción aspiratoria (siempre en dirección paralela al nervio facial) y deben evaluarse los datos clínicos para valorar la hospitalización. ${ }^{3}$ Algunos métodos quirúrgicos son:

- Ligadura del conducto de Stenon.

- Neuronectomía timpánica.

- Parotidectomía. ${ }^{1,8}$

\section{Complicaciones}

De no tratarse de forma oportuna y adecuada se pueden presentar complicaciones como: necrosis glandular, parálisis facial, absceso de la glándula salival, reaparición de la infección, diseminación de la infección (angina de Ludwig) y fístulas. ${ }^{1,6,37-39}$

\section{Discusión}

El término sialoadenitis bacteriana aguda se introdujo por primera vez en $1828^{1}$ y, aunque en la literatura especializada existen diversos términos para referirse a esta enfermedad, en el Instituto Nacional de Pediatría, centro hospitalario de tercer nivel de atención, consideramos más adecuado el termino sialoadenitis bacteriana crónica recurrente de la infancia ya que es una inflamación del parénquima glandular (sialoadenitis) debida a un proceso bacteriano, con dos o más episodios activos separados por lapsos asintomáticos (crónico recurrente) en pacientes pediátricos.

La duración del tratamiento antimicrobiano es de siete días. En algunos pacientes tratados en el Instituto Nacional de Pediatría el cuadro clínico permanece por más de siete días, pese al tratamiento antimicrobiano, por lo que su administración se prolonga hasta diez días ya que la administración frecuente de antimicrobianos en edades tempranas de la vida trae como consecuencia múltiples efectos nocivos.

Baszis $^{3}$ propone como factor predisponente algunas afecciones dentales, específicamente caries, lo que coincide con lo reportado por Ramírez, ${ }^{8}$ quien además sugiere que los microorganismos propios de la cavidad bucal pueden ser agentes desencadenantes. En el Instituto Nacional de Pediatría se ha encontrado, además de los factores antes mencionados, una relación importante entre algunas enfermedades propias del oído (otitis media) y las infecciones de las vías aéreas superiores, con la aparición de la sialoadenitis; probablemente por la relación anatómica que existe con la glándula parótida. 


\section{CONCLUSIONES}

Las infecciones agudas y crónicas, principalmente de origen bacteriano como en esta enfermedad, tienen un amplio espectro de severidad que depende en gran medida de la condición sistémica del paciente. Este es el caso de los pacientes pediátricos que acuden al Instituto Nacional de Pediatría, por lo que se debe evaluar integralmente al paciente para brindarle un adecuado y oportuno plan de tratamiento.

La sialoadenitis bacteriana crónica recurrente de la infancia, al ser una afección propia del aparato estomatognático, es una enfermedad importante que debe conocer el estomatólogo pediatra. Debido a que en los informes de la literatura no existen datos específicos de sialoadenitis bacteriana crónica recurrente en la población pediátrica mexicana, consideramos importante realizar un estudio epidemiológico para obtener datos significativos que permitan determinar algunos factores causales y para realizar tratamientos preventivos que disminuyan la incidencia de este padecimiento.

\section{REFERENCIAS}

1. Ospina MA, Del Valle RA, Naranjo RR. Inflamación de glándulas salivales. Revisión bibliográfica. Revista Facultad de Odontología Universidad de Antioquia 2003;15(1):1-12.

2. Stoesser N, Pocock J, Moore CE, Soeng S, Chhat HP, Sar P, et al. Pediatric suppurative parotitis in Cambodia between 2007 and 2011. Pediatr Infect Dis J 2012;31(8):865-8.

3. Baszis K, Toib D, Cooper M, French A, White A. Recurrent parotitis as a presentation of primary pediatric Sjögren syndrome. Pediatrics 2012;129(1):e179-82.

4. Brook I. Aerobic and anaerobic microbiology of suppurative sialadenitis. J Med Microbiol 2002;51(6):526-9.

5. Vives IA, Insua AC. Parotiditis crónica recidivante con trastornos inmunológicos asociados. Rev Cubana Pediatr 2007;79(4):1-6.

6. Vila MD, Pi OA, Giral RT, González-Longoria CR. Aplicación de propóleos en el tratamiento de la parotiditis crónica del niño. Revista Cubana de Estomatología 2009;46(4):41-48.

7. Zenk J, Koch $\mathrm{M}$, Klintworth $\mathrm{N}$, Iro H. Chronic recurrent parotitis. HNO 2010;58(3):237-43.
8. Ramírez OJ, Peña VA. Enfoque y tratamiento actual de la parotiditis recurrente. Revisión sistemática de la literatura. Acta de Otorrinolaringología \& Cirugía de Cabeza y Cuello 2010;38(1):39-44.

9. Rouvière H. Anatomía humana. Tomo 1. Cabeza y cuello. 11a ed. Barcelona, España: Editorial Masson; 2005. pp. 479483.

10. Henry HW. Anatomía para cirujanos dentistas. Editorial Harla, 1983; pp. 87-91.

11. Valcárcel LIJ, Marsán SV, Fernández GM. Caracterización clínica de la parotiditis recurrente en niños. Hospital Pediátrico William Soler. Revista Habanera de Ciencias Médicas 2011;10(1):19-26.

12. Park JW. Recurrent parotitis in childhood. Clin Pediatr (Phila) 1992;31(4):254-5.

13. De la Teja AE, Escudero CA, Elías MG, Cadena GA, Téllez RJ, Belmont LF, et al. Infecciones de la cavidad oral (III de III). Infecciones no odontogénicas. Acta Pediatr Méx 1999;20(5):263-5.

14. Al-Dajani N, Wootton SH. Cervical lymphadenitis, suppurative parotitis, thyroiditis, and infected cysts. Infect Dis Clin North Am 2007;21(2):523-41.

15. Lazos OM. Sialadenitis poco frecuentes. Conceptos actuales. Rev Med Hosp Gen Mex 2010;73(2):120-128.

16. López PE, Vila SL, Cacharrón CT, Moreno ÁA. Juvenile recurrent parotitis and natural killer cells deficiency. An Pediatr (Barc) 2012;77(3):216-7.

17. Brook I. Diagnosis and management of parotitis. Arch Otolaryngol Head Neck Surg 1992;118(5):469-71.

18. De la Teja AE, Durán GA, Espinosa VL, Ramírez MJA. Manifestaciones estomatológicas de los trastornos sistémicos más frecuentes en el Instituto Nacional de Pediatría. Revisión de la literatura y estadísticas del Instituto. Acta Pediatr Mex 2008;29(4):189-99.

19. Özdemir H, Karbuz A, Ciftçi E, Fitöz S, Ince E, Doğru U. Acute neonatal suppurative parotitis: a case report and review of the literature. Int J Infect Dis 2011;15(7):e500-2.

20. Brook I. Suppurative parotitis caused by anaerobic bacteria in newborns. Pediatr Infect Dis J 2002;21(1):81-2.

21. Brook I, Frazier EH, Thompson DH. Aerobic and anaerobic microbiology of acute suppurative parotitis. Laryngoscope 1991;101(2):170-2.

22. Stong BC, Sipp JA, Sobol SE. Pediatric parotitis: a5-year review at a tertiary care pediatric institution. Int J Pediatr Otorhinolaryngol 2006;70(3):541-4.

23. Katz $P$, Hartl DM, Guerre A. Treatment of juvenile recurrent parotitis. Otolaryngol Clin North Am 2009;42(6):1087-91.

24. Hernández GM, Ayala GF, Manrique CJ, Hernández PR, Guido GX, Martínez RM. Sialoadenitis en paciente pediátrico. Presentación de un caso. Revista de especialidades Médico-Quirúrgicas ISSSTE 2007;12(2):75-78.

25. Schneider $H$, Koch $M$, Künzel J, Gillespie MB, Grundtner $\mathrm{P}$, Iro $\mathrm{H}$, et al. Juvenile recurrent parotitis: A retrospective 
Ávila-Sánchez C et al. Sialoadenitis bacteriana crónica de la infancia

comparison of sialendoscopy versus conservative therapy. Laryngoscope 2014;124(2):451-5.

26. González GLI, Guillen FG. Recurrent parotitis: sialoendoscopy and botulinum toxin as alternatives. Indian J Dent Res 2012;23(4):554-5.

27. Hackett AM, Baranano CF, Reed M, Duvvuri U, Smith RJ, Mehta D. Sialoendoscopy for the treatment of pediatric salivary gland disorders. Arch Otolaryngol Head Neck Surg 2012;138(10):912-5.

28. Capaccio P, Sigismund PE, Luca N, Marchisio P, Pignataro L. Modern management of juvenile recurrent parotitis. J Laryngol Otol 2012;126(12):1254-60.

29. Gary C, Kluka EA, Schaitkin B, Walvekar RR. Interventional sialendoscopy for treatment of juvenile recurrent parotitis. J Indian Assoc Pediatr Surg 2011;16(4):132-6.

30. Canzi P, Occhini A, Pagella F, Marchal F, Benazzo M. Sialendoscopy in juvenile recurrent parotitis: a review of the literature. Acta Otorhinolaryngol Ital 2013;33(6):367-373.

31. Sodhi KS, Bartlett M, Prabhu NK. Role of high resolution ultrasound in parotid lesions in children. Int J Pediatr Otorhinolaryngol 2011;75(11):1353-8.

32. Carrillo RE, Núñez BJ, Balbuena CA. Parotiditis asociada a intubación orotraqueal. Reporte de un caso y revisión de la literatura. Revista Mexicana de Anestesiología 2007;30(3):176-79.

33. Gómez GR, Gómez CM, Cedillo HA. Parotiditis endémica. Revista ADM 2003;LX(4):150-54.

34. Bourlon MT, Chapa M, Chablé MF, Hernández CJ. Enfermedad linfoproliferativa multiorgánica asociada a inmunoglobulina G4. Gaceta Médica de México 2011;147:545-50.

35. Romero FJ, Zetina VV, Márquez RL. Sialadenitis crónica esclerosante (tumor de Kuttner) en glándulas submaxilares relacionada con enfermedad de IgG4. Revista Mexicana de Cirugía Bucal y Maxilofacial 2012;8(3): 92-97.

36. De la Teja AE, Cortés MV, Durán GA, Espinosa VL. Factores de riesgo para las urgencias estomatológicas en el Instituto Nacional de Pediatría. Acta Pediatr Mex 2008;29(6):329-35.

37. Recio LC, Gutierrez PJ, Infante CP, Torres LD. Patología de las glándulas salivares. Revista Secib On Line 2004;1:1-22.

38. Baszis K, Toib D, Cooper M, French A, White A. Recurrent parotitis as a presentation of primary pediatric Sjögren syndrome. Pediatrics 2012;129(1):e179-82.

39. Alp H, Orbak Z, Erdogan T, Karabag K, Gursan N. Recurrent parotitis as a first manifestation in a child with primary Sjogren's syndrome. West Indian Med J 2011;60(6):685-7.

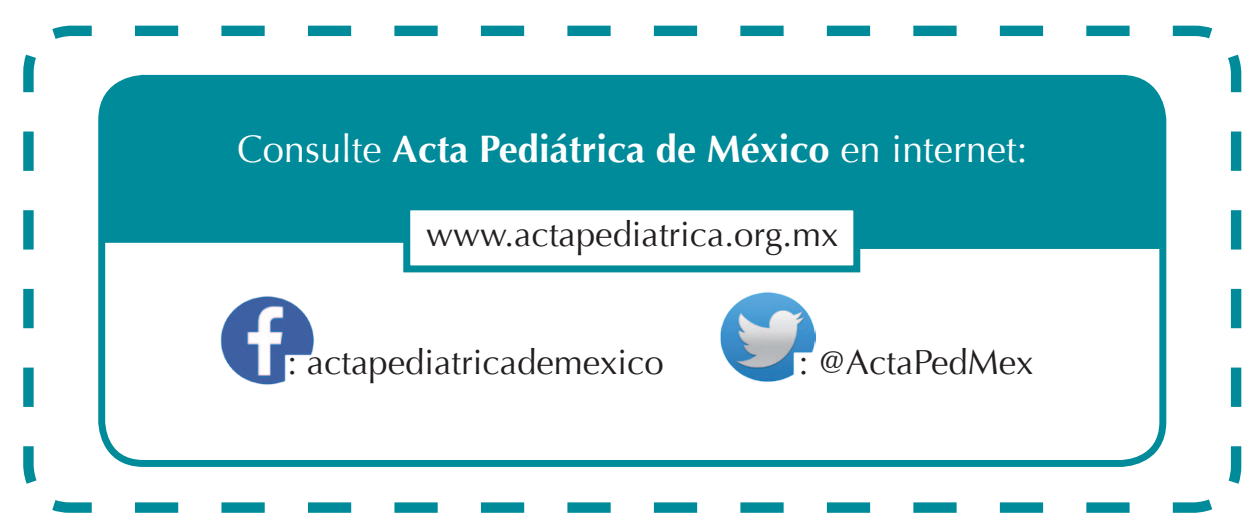

